\title{
0 Conselho de Estado e o complexo funcionamento do governo monárquico no Brasil do século XIX
}

The State Council and the Complex

Engineering of the Monarchical

Government in 19th Century Brazil

\section{Cecília Helena de Salles Oliveira}

Professora no Museu Paulista da

Universidade de São Paulo

\section{Resumo}

Este texto procura sublinhar e desenvolver alguns dos questionamentos apontados por José Reinaldo de Lima Lopes no artigo "Consultas da Seção de Justiça do Conselho de Estado (1842-1889). A formação da cultura jurídica brasileira". Problematiza o papel do Conselho de Estado, no segundo reinado, especialmente no tocante às relações que manteve com o Poder Moderador no âmbito da prática de governar e no dos princípios propostos pela Carta constitucional de 1824.

\section{Abstract}

This article aims to highlight and to further develop some aspects pointed out by José Reinaldo Lima Lopes in his essay "Brazilian legal culture in the XIX Century: the role of the Council of State (Division of affairs of justice)". It calls into question the State Council's purposes, during the Second Reign, mainly its relations with Royal Power, considering governing practices and the principles built up by the 1824 Constitution.

\section{Palavras-chave}

história politica, Estado / formas de governo, monarquia, Império do Brasil, poder moderador, Conselho de Estado

\section{Keywords}

political history, State / forms of government, monarchy, Brazilian Empire, moderating power, State Council 
ROSANVALLON, Pierre. La monarchie impossible. Paris: Fayard, 1994.

0 termo se refere a um governo limitado pelo direito e pelas liberdades civis, o que salvaguardava os cidadãos dos abusos do poder atribuídos à monarquia absoluta. Ver, também, as considerações de Hanna Arendt, na obra Sobre la Revolución. Madrid, Ediciones de la Revista de Ocidente, 1967.

Lei $n$. 234 de 23 de novembro de 1841 , criando um Conselho de Estado. In: RODRIGUES, José Honório. 0 Conselho de Estado. 0 quinto poder? Brasilia: Senado Federal, 1978. p.401.
...L'histoire constitucionnelle de la période [1814 a 1848] reste, elle, encore à découvrir. Pierre Rosanvallon

No livro La monarchie impossible1, Pierre Rosanvallon discute a presença de duas formas de compreensão da história política no século XIX, referenciando-se na experiência francesa, registrada tanto em discursos de época quanto na historiografia posterior. Há uma história que acentua a tradição jacobina e a reiterada tentativa de absolutização da soberania do povo. E há uma história voltada para a extensão das liberdades e para a formação do governo representativo. Segundo o autor, essas abordagens distintas e o fato de se privilegiar geralmente a tradição jacobina teriam promovido o distanciamento entre uma história das representações e das lutas políticas e uma história das instituições. Contrariando essa tendência, propõe uma investida na direção de investigar-se as articulações e contradições entre essas duas dimensões da história, lidando-se com o espirito jacobino e também com o que haveria de "espírito inglês" (para usar suas palavras) nas instituições e nas práticas políticas francesas, o que viria a contribuir, a seu ver, para o entendimento mais acurado das especificidades nacionais no século XIX.

Fundamentando-se nesses argumentos é que Rosanvallon analisou as Cartas constitucionais francesas de 1814 e 1830 que, tal como outros textos constitucionais, serviram de inspiração para os legisladores brasileiros, durante a primeira metade do século XIX, mais especificamente entre 1823 e 1841, período de elaboração da Carta constitucional do Império e das reformulações que sofreu. Para Rosanvallon, aqueles documentos expressaram a aprendizagem dos modos de fazer a política moderna na França, pois teriam lançado as bases para a superação da noção de "monarquia limitada" desdobrando-a em monarquia parlamentar².

0 artigo formulado por José Reinaldo de Lima Lopes, "Consultas da Seção de Justiça do Conselho de Estado (1842-1889). A formação da cultura juridica brasileira", expõe hipóteses e considerações voltadas justamente para uma história das instituições, ao centrar-se no Conselho de Estado, recomposto a partir de 1842, e nos significados da ação desse órgão em termos da operacionalidade da justiça e do Direito no Brasil da época. Sua argumentação, no entanto, pode contribuir para a compreensão de fundamentos e práticas governativas, ou seja, para o deslindamento de aspectos da dinâmica da luta política e do simultâneo delienamento do Estado imperial, avivando o debate em torno das especificidades da monarquia na segunda metade do século XIX.

Assim, poder-se-ia conjeturar, seguindo proposta de Rosanvallon, se o estudo do Conselho de Estado não viria a lançar luzes sobre a trajetória através da qual, concomitantemente à divergências partidárias e à controvérsias entre projetos políticos, a monarquia constitucional prevista na Carta de 1824 transformou-se, ao longo do segundo reinado, em experiência singular de parlamentarismo, em função dos modos históricos pelos quais a Carta foi interpretada e aplicada.

Problematizar o lugar ocupado pelo Conselho de Estado, após 1842, representa questionar a configuração da monarquia e a concepção de Poder Moderador, naquela quadra, bem como as maneiras pelas quais foi exercido, levando-se em conta a lei de 23 de novembro de $1841^{3}$, bem como o título $5^{\circ}$. da Carta constitucional, dedicado ao Imperador, onde estavam 
Carta de Lei de 25 de março de 1824. Coleção das Leis do Brasil. Rio de Janeiro: Imprensa Nacional, v. 1823/1824, anexo, p.7-36, 1891 arroladas as atribuições do poder moderador ( cap. 1); as prerrogativas do poder executivo (cap. 2) e a posição que ministros e conselheiros de Estado deveriam ocupar junto a esses poderes, já que ambos eram nomeados diretamente pelo governante e deveriam coadjuvá-lo nas funções de Chefe da Nação e chefe do poder executivo ${ }^{4}$.

Nesse sentido, os comentários que formulei se concentram nos primeiros três tópicos do artigo de Lima Lopes. Procuro explorar uma das metas essenciais do texto que é, a meu ver, a de compreender a formação do pensamento jurídico no Brasil, na segunda metade do século XIX, do ponto de vista da história do Direito e dos fundamentos desse Direito.

\section{0 lugar jurídico-político do Conselho de Estado}

Referenciando-se em argumentos elaborados por políticos e juristas do segundo reinado, especialmente no momento em que se discutia a reforma no poder judiciário, em 1871, a exemplo de Nabuco de Araújo, Cândido Mendes e Lafayette Rodrigues Pereira, Lima Lopes observa que, de acordo com esses protagonistas, não teria se constituído uma jurisprudência nacional e de orientação aos tribunais. Havia magistrados, mas não um poder judiciário independente que fosse guarda da constituição e implementasse unidade de vistas na interpretação e aplicação do Direito. Pelas considerações desses políticos, poder-se-ia conjeturar que a cultura jurídica estava lastreada na prática cotidiana e nos costumes locais e não necessariamente em um lugar de produção específico, como as Academias de Direito, por exemplo.

Por essa via, conforme Lopes, seria possível estabelecer uma vinculação entre argumentos de juristas do século XIX e considerações de estudiosos do Direito brasileiro no século $X X$, já que ambos atestam carências ao pensamento jurídico no Brasil, mas por meio de diferentes abordagens: no século XIX ressaltava-se, especialmente nas décadas finais do século, a falta de orientação uniforme às instituições, a despeito de reconhecer-se uma cultura jurídica; em contrapartida, estudiosos do século XX, sublinharam que, em função do envolvimento da justiça com a política, não havia se delineado uma cultura jurídica.

0 Autor interroga, então, esses argumentos. Aponta que, por seu caráter instituidor, a cultura jurídica no Brasil do século XIX foi marcada, entre outros aspectos, pela praticidade, pois emergiu no e do movimento de instituição do Estado nacional, entrelaçando-se à invenção das instâncias de atuação política. Entretanto, ao mesmo tempo em que reconhece essa cultura, indaga sobre o espaço de sua produção e sobre suas significações. Qual seria esse lugar se, conforme pondera o Autor, as Academias de Direito e o Supremo Tribunal de Justiça, na visão de políticos e juristas dos finais do século XIX, pareciam não cumprir esse papel?

Buscando encaminhar a questão propõe - e essa é a tese central do artigo - que o Conselho de Estado, órgão auxiliar do Poder Moderador, seria o locus da alta cultura jurídica, em razão das atribuições constitucionais que adquiriu e do modo como teria funcionado após a já citada lei de 23 de novembro de 1841.

Cabe lembrar que, conforme a Carta constitucional de 1824, os conselheiros de Estado eram vitalícios e em número de 10; dentre eles não estavam compreendidos os ministros, a não ser que fossem nomeados explicitamente para esse fim. Previa-se que o Conselho seria ouvido "em todos os negócios graves e medidas gerais da pública administração; principal- 
Ver, entre outros: CASTRO, Paulo Pereira. A experiência republicana/ Politica e administração entre 1840 e 1848. In: HOLANDA, Sérgio Buarque (org.) História Geral da Civilização Brasileira. Tomo II, Vol.2, 2a ${ }^{\text {a }}$ edição. São Paulo: Difel, 1967. p.9-69 e p. 509-540; BARBOSA, Silvana Mota. A sphinge monárquica. 2001. Tese (Doutorado). Universidade de Campinas, Campinas, 2001.

Refiro-me, particularmente, ao confronto nesse período entre, pelo menos duas propostas bastante distintas em relação à figura do rei na monarquia portuguesa. Uma, produzida e divulgada por José da Silva Lisboa na obra Memória dos Benefícios do Governo Del Rei

D. João VI, escrita em 1817 e editada em 1818, para celebrar a coroação de D. João na cidade do Rio de Janeiro; e outra, divulgada por meio dos discursos e ações dos revolucionários de Pernambuco, em 1817. Ver: OLIVEIRA, Cecilia Helena de Salles. A Astúcia Liberal: relações de mercado e projetos políticos no Rio de Janeiro, 1820/1824; e BERNARDES, Denis Antônio Mendonça. O Patriotismo constitucional: Pernambuco, 1820/1822. São Paulo: Hucitec/ UFPE/FAPESP, 2006.

Refiro-me à ampla divulgação, no Rio de Janeiro e demais provincias, das Bases da futura Constituição a ser elaborada pelas Cortes em Lisboa e ao retorno, em abril de 1821 , de D. João a Portugal. Coleção das Leis do Brasil. Rio de Janeiro: Imprensa Nacional, vol. 1821, partes I e II, 1891.

0 instrumento jurídico de 1824 , por ter sido outorgado pelo Imperador, chama-se "Carta constitucional" e assim foi tratado durante o primeiro reinado, particularmente pelas oposições parlamentares a D. Pedro. A partir, entretanto, das reformas de 1834 e 1840 , discutidas e promulgadas pela Câmara e pelo Senado, tornou-se corrente o uso da expressão "Constituição do Império".

Ver: OLIVEIRA, Cecilia Helena de Salles. Nação e cidadania. A Constituição de 1824 e suas implicações políticas. Horizontes. Bragança Paulista: Universidade São Francisco, vol. 16, p.11-37, 1998. mente sobre a declaração da guerra, ajustes de paz, negociações com nações estrangeiras, assim como em todas as ocasiões, em que o Imperador se proponha a exercer qualquer das atribuições do poder moderador" (art.142).

Assim, o Conselho seria consultado: nas nomeações de senadores; na convocação extraordinária da Assembléia Geral; na sanção a decretos e resoluções do poder legislativo e dos conselhos provinciais; na prorrogação e adiamento do poder legislativo ou dissolução da Câmara dos Deputados; na suspensão de magistrados, na aplicação do direito de graça e nos casos de anistia.(art.101). Havia, apenas, uma exceção: a nomeação e demissão de ministros, incumbência própria ao Imperador.

Não é demais sublinhar que, a despeito do cerrado debate que durante o século XIX se desenvolveu na Câmara, no Senado e na imprensa sobre o lugar e as atribuições a serem exercidos pelo monarca ${ }^{5}$, a instituição do Poder Moderador e o Conselho de Estado, por vezes alvos de críticas contundentes, não foram suprimidos a não ser, no caso do Conselho, por curto período. 0 que só vem reforçar a pertinência de estudar-se, simultaneamente às interpretações que sofreram as teorias políticas da época e aos conflitos de natureza partidária, a relevância do Poder Moderador e do Conselho em termos do exercício de governar, do encaminhamento de dispositivos legais, bem como da formulação e aplicabilidade da justiça.

Destaco três momentos que, a meu ver, marcaram o debate em torno do Poder Moderador e do Conselho de Estado e que me parece relevante considerar para compreender e desdobrar propostas apresentadas por Lima Lopes.

\section{0 Conselho de Estado: uma proposta de cronologia e de interpretação}

0 primeiro desses momentos corresponderia ao periodo entre $1821 \mathrm{e}$ 1824, quando se delinearam os princípios constitucionais incorporados na configuração do governo do Reino e depois Império do Brasil. Apesar do debate acerca dos fundamentos da monarquia portuguesa e do governo de D. João VI estar explicitado em obras, folhetos e documentos de cunho oficial datados desde, pelo menos, de 18176, foi a Revolução, em Portugal, e a repercussão dos projetos defendidos pelos revolucionários vintistas em torno da construção de governo representativo, especialmente a partir de março e abril de 18217 , que avivaram as discussões, quer na Corte do Rio de Janeiro, quer nas províncias.

Lembro, nesse sentido, que a Carta constitucional de 18248 reuniu sob redação específica princípios e procedimentos que, de forma explícita ou não, estiveram presentes em diferentes constituições anteriores, indicando que os legisladores brasileiros selecionaram e recriaram concepções e práticas que faziam parte do solo político e cultural ocidental à época, dando-Ihes matiz singular 9 . Refiro-me, especialmente, à Constituição francesa de 1799, a do Consulado, mencionada por Lima Lopes, na qual o Conselho de Estado que auxiliava o Primeiro Cônsul era por ele indicado e tinha por atribuições, entre outras, preparar e redigir projetos de lei de iniciativa do executivo e encaminhar pendências de natureza administrativa; à Constituição espanhola de 1812 que traçou a estrutura de uma monarquia moderada hereditária, na qual o rei exercia o poder executivo através de seus ministros e com o auxilio de Conselho de Estado, reunindo todas as atribuições que, em 1824, seriam divididas entre os poderes Executivo e 0 Moderador, embora nesse caso, o Conselho fosse nomeado pelo rei a partir 
Para consultar os documentos citados, ver: ROSANVALLON, Pierre. La monarchie impossible. Paris: Fayard, 1994; MORAES, Alexandre José de Mello. História do Brasil Reino e Brasil Império. São Paulo/Belo Horizonte: EDUSP/Itatiaia, 1982, 2 vols.

\section{1}

Consultar, além das obras já citadas de Paulo Pereira de Castro e de Silvana Mota Barbosa, os livros de Maria de Lourdes Mônaco Janotti. A Balaiada. São Paulo: Brasiliense, 1987; e de Maria de Lourdes Viana Lyra. Um Império em construção. São Paulo: Atual, 2002.

\section{2}

Segundo Silvana Mota Barbosa, a partir desse decreto do poder moderador, os membros do gabinete eram escolhidos pelo Presidente do Conselho de Ministros, o que dá margem à interpretação de que o Imperador deixava de exercer a liberdade de escolher todo o ministério. De 1847 até 1889, a grande maioria dos presidentes de conselho de ministros pertencia ao Senado e ao Conselho de Estado. Ver: BARBOSA, Silvana Mota. A sphinge monárquica. 2001. Tese (Doutorado). Universidade de Campinas, Campinas, 2001.

\section{3}

Entre 1831 e 1834, dentre as várias propostas para reformar artigos constitucionais, havia uma que previa a supressão do poder moderador bem como do conselho de Estado, o que representaria a promulgação de outra constituição. Entretanto, o projeto, designado Constituição de Pouso Alegre, e os princípios que apresentava foram obstados no Senado, principalmente, e depois na Câmara, após a tentativa de golpe de 1832. Ver: os artigos já citados de Paulo Pereira de Castro; o texto da Constituição de Pouso Alegre pode ser encontrado na obra Textos políticos de História do Brasil, organizada por Bonavides e Amaral, disponivel no site www.cebela.org.br/textos políticos/textos políticos.htm. É importante ressaltar que, nessa proposta de julho de 1832, com exceção do poder de dissolver a Câmara que foi suprimido, todas as demais atribuições do poder moderador foram arroladas como atribuições do executivo e exercidas pelo monarca, através de seus ministros.

\section{4}

Lei de 14 de junho de 1831, art. 10 e art. 19 In: RODRIGUES, José Honório (org). Atas do Conselho de Estado. Brasilia: Senado Federal, Vol.II, 1973, p.355-ss.

\section{5}

Ver: RODRIGUES, José Honório. O Conselho de Estado. 0 quinto poder? Brasília: Senado Federal, 1978. p. 143-ss.

\section{6}

Ibidem. Lei n. 234 de 23 de novembro de 1841, p.401-ss de listas triplices elaboradas pelas Cortes; à Constituição francesa de 1814, na qual, embora não haja menção especifica a Conselho de Estado, reforçava-se a iniciativa legislativa do rei, bem como o entendimento de que a justiça emanava do monarca; e à Constituição portuguesa de 1822 que recriou sem modificações substanciais pressupostos de $1812^{10}$.

Poder-se-ia considerar o período entre 1831-1847 como sendo o segundo momento a que me referi. Foi assinalado tanto por conflitos que envolveram a definição de novos grupos dirigentes na Corte e nas províncias quanto por intensas contendas parlamentares em torno da promulgação de alterações no texto constitucional ${ }^{11}$. Durante essa época, o Conselho de Estado foi suprimido e posteriormente recriado sob condições inéditas, assim como foi decidida a criação do cargo de Presidente do Conselho de Ministros, o que também modificou a relação do Imperador com os membros do poder executivo ${ }^{12}$.

Este momento foi marcado, igualmente, por experiência governativa que exerceu profundas repercussões nos anos que se seguiram, e que resultou, entre outras circunstâncias, da Lei da Regência e do confronto, que vinha se verificando antes mesmo da Abdicação, entre deputados na Câmara e membros do Conselho de Estado que tinham sido nomeados por D. Pedro I. Esses episódios contribuíram para que, apesar da atuação contrária de membros do Senado, o Ato Adicional, em 1834, incluisse artigo específico sobre a supressão do Conselho de Estado13. A Lei da Regência - que explicitou enfrentamentos entre forças políticas na Câmara contrárias aos grupos que deram sustentação ao governo de D. Pedro e que se concentravam no Senado e no Conselho de Estado - não só definiu a eleição da Regência permanente como delimitou o espaço de atuação do governo, estabelecendo que os Regentes poderiam exercer todas as atribuições dos poderes Moderador e Executivo, com a referenda obrigatória dos ministros em ambos os casos, mas com algumas importantes exceções. A Regência não poderia dissolver a Câmara, conceder anistia ou títulos e honras e nomear conselheiros de estado, "salvo no caso em que fiquem menos de três"14.

Desse modo, a Câmara, com o aval do Senado, criava condições para práticas governativas diversas das que haviam preponderado no primeiro reinado, minimizando o espaço do Conselho de Estado. Entretanto, se o Ato Adicional manteve o Poder Moderador mas suprimiu o Conselho, desde 1837 vários debates no Senado e depois na Câmara apontavam a retomada da discussão sobre as atribuições do Conselho e sua composição, ao mesmo tempo em que se discutia, também, a possibilidade da maioridade ${ }^{15}$.

Em maio de 1841, a Fala do Trono mencionava abertamente a propositura do ministério em defender a recomposição do Conselho e, em 23 de novembro do mesmo ano, o Conselho de Estado foi recriado. Mas, há diferenças significativas entre o texto da Lei e o texto constitucional datado de 1824. Do Conselho de Estado passaram a fazer parte os ministros, além do que o Conselho foi dividido em seções, correspondentes, grosso modo, às incumbências de cada ministério. Essa organização do Conselho era uma proposta que, desde 1831, estava em pauta no Parlamento, prevendo-se, ainda, que o Conselho pleno seria presidido pelo Imperador, muito embora as Seções pudessem ser convocadas e presididas pelos ministros das respectivas pastas. Ao lado disso, não haveria mais a obrigatoriedade de audiência do Conselho por parte do Imperador na resolução de questões atinentes ao exercício do Poder Moderador ${ }^{16}$. 
RODRIGUES, José Honório. 0 Conselho de Estado. 0 quinto poder? Brasília: Senado Federal, 1978. Regulamento n. 124, de 5 de fevereiro de 1842. p.404-ss.

\section{8}

BUENO, José Antônio Pimenta ( Marquês de São Vicente). Direito Público brasileiro e análise da Constituição do Império (1a. ed. 1857). $2^{\text {a }}$ edição. Brasilia: Senado federal, 1978; SOUZA, Paulino José Soares (Visconde de Uruguai). Ensaio sobre direito administrativo. Rio de Janeiro: Tipografia Nacional, 1862, 2 vols.

19

Ver CARVALHO, José Murilo. A construção da ordem/ Teatro de sombras. Rio de Janeiro: Relume Dumará, 1996; e FAORO, Raymundo. Existe um pensamento político brasileiro. São Paulo: Ática, 1994

\section{0}

Ver: HOLANDA, Sérgio Buarque. De Império à República. História Geral da Civilização Brasileira. Tomo II, Vol. 5. São Pauo: Difel, 1972. Outra proposta de leitura sobre a prática do poder moderador, especificamente no final do Império, pode ser encontrada no artigo de Célio Ricardo Tasinafo, 0 título 50. da Constituição do Império, os reposteiros da política imperial e a abolição da escravatura. In: MALATIAN, T., SAENZ, M. \& MANOEL, I. (org) As múltiplas dimensões da politica e da narrativa. Franca: Editora Olho d'Água/ Programa de PósGraduação em História, 2003. p.77-90.

21

Ver: OLIVEIRA, Cecilia Helena de Salles. Introdução. In: (org). Zacarias de Góis e Vasconcelos. São Paulo: Editora 34, 2002. p.9-58.

\section{2}

0 Manifesto foi publicado na obra organizada por Vamireh Chacon. História dos partidos politicos brasileiros. Brasilia: UnB, 1985. Análise enriquecedora e estimulante sobre o Manifesto encontra-se na tese de doutoramento de Maria Stella Martins Bresciani. Liberalismo: ideologia e controle social. São Paulo, 1850/1910. 1976. 2 vols. Tese (Doutorado). Universidade de São Paulo, São Paulo, 1976
A Lei foi complementada pelo Regulamento de fevereiro de $1842^{17}$, segundo o qual as seções do Conselho seriam: negócios do Império, da Justiça e estrangeiros, da fazenda e da guerra e marinha. Estabeleceu-se que os ministros não poderiam votar ou assistir as votações nos casos específicos da dissolução do ministério e da câmara, explicitando-se que, dentre as atribuições do Conselho, estavam a discussão e a propositura de questões de natureza não contenciosa, como o exame das leis provinciais e a elaboração de regulamentos ou instruções, e de natureza contenciosa, a exemplo dos conflitos de jurisdição entre autoridades e orientações de caráter administrativo e jurídico.

Finalmente, é possivel tomar os anos entre 1857 e 1870 como marcos de um terceiro momento do debate em questão. Ao contrário dos demais, foi este um período bastante discutido pela bibliografia dedicada à história do Império, em função de coincidir com a edição de obras de natureza político-jurídica que se transformaram em referências para o estudo do Estado monárquico e do Direito no século XIX. Refiro-me particularmente às obras de Pimenta Bueno e do Visconde de Uruguai, ambos conselheiros de Estado 18 .

Mas, ao mesmo tempo, essa época registrou tensas controvérsias a respeito da atuação do rei em monarquias constitucionais e o governo de D. Pedro II, em particular, tornou-se alvo de intensa discussão. No decorrer dessas disputas, ganharam contornos específicos argumentos contraditórios que há muito estavam presentes nas falas de ministros e parlamentares de diversos matizes partidários e que, talvez em razão do caráter genérico que adquiriram nessa época, passaram também a povoar as páginas de historiadores preocupados em interpretar o Império ${ }^{19}$. Refiro-me, especialmente, às noções de que o exercício do poder moderador não coadunava com a prática de uma monarquia parlamentar; de que o poder moderador era sinônimo de poder pessoal e imperialismo, no sentido da Coroa sobrepor-se à situação política, invertendo-a a seu bel prazer e arbitrio; e, inversamente, a de que o poder moderador era essencial para preservar o Império, garantindo sua integridade territorial, obstando a desorganização social e, ainda, impedindo um enfrentamento partidário direto, pois nesse argumento o poder moderador possibilitava a alternância dos partidos de forma a minimizar arestas entre grupos concorrentes e a aplainar diferenças significativas entre liberais e conservadores 20 .

0 embate protagonizado por esses argumentos - e que aparentemente colocava frente a frente conservadores "emperrados" e liberais "progressistas"21 - teria como ponto de inflexão os episódios de julho de 1868, considerados por contemporâneos, como Nabuco de Araújo e Zacarias de Góis, e posteriormente por Joaquim Nabuco e historiadores que escreveram sobre o Império na primeira metade do século $X X_{1}$ o marco do início da derrocada da monarquia, em função da inversão política que teria sido promovida por Pedro II e que colocou os chamados "progressistas" fora do poder por dez anos; disso resultou, entre outras tantas circunstâncias, uma profunda reorganização partidária com o surgimento de um novo partido liberal e um novo partido conservador e com a reunião de importantes liberais históricos nas agremiações republicanas então criadas primeiro no Rio de Janeiro e depois em São Paulo.

0 Manifesto de $1870^{22}$, do partido republicano fluminense, consolida a memória com a qual aprendemos a conhecer o Poder Moderador e o Conselho de Estado - expressão de despotismo; fruto da ingerência da 
23

Consultar, entre outras, as já citadas obras de CARVALHO, José Murilo. A construção da ordem/ Teatro de sombras. Rio de Janeiro: Relume Dumará, 1996; e FAORO, Raymundo. Existe um pensamento político brasileiro. São Paulo: Ática, 1994; e HOLANDA, Sérgio Buarque (org.) História Geral da Civilização Brasileira. Tomo II, Vol.2, 2a. edição. São Paulo: Difel, 1967. Ver, também, NABUCO, Joaquim. Um estadista do Império. Rio de Janeiro: Topbooks, 1997, 2 vols.

24

Sobre a questão, consultar: JANOTTI, Maria de Lourdes. A falsa dialética: Justiniano José da Rocha. Revista Brasileira de História. São Paulo: ANPUH, N.3, 1982.; VESENTINI, Carlos Alberto. A teia do fato. São Paulo: Hucitec/ PPGHS, 1997.

\section{5}

MATTOS, IImar. 0 lavrador e o construtor. 0 Visconde de Uruguai e a construção do Estado imperial. In: PRADO, Maria Emilia. 0 Estado como vocação, p. 216.

26

FAORO, Raymundo, op. cit., p.128.

\section{7}

Ver: RODRIGUES, José Honório. 0 Conselho de Estado. 0 quinto poder? Brasília: Senado Federal, 1978.; TORRES, João Camilo de Oliveira. 0 Conselho de Estado. Rio de Janeiro: Edições GRD, 1965.
Coroa que bloqueou o desdobramento da revolução da Independência, com a dissolução da Constituinte, em 1823; manifestação de atraso, do peso das heranças coloniais e da incompatibilidade da monarquia brasileira com os "verdadeiros" princípios constitucionais e parlamentaristas. Isto porque, a Coroa teria em suas mãos o arbitrio para inverter a situação política, desrespeitando a maioria e a opinião nacional expressas nas eleições, e favorecendo pleitos fraudados que só faziam perdurar a posição de Senadores e Conselheiros vitalícios, desprezando-se o espaço da Câmara e as demandas da sociedade.

A bibliografia mais conhecida sobre o tema 23 recorre, em grande parte, a registros e argumentações produzidos nessas décadas para avaliar todo o período monárquico, sem considerar o caráter político dessas fontes 24 e o quadro de lutas em que se inscreveram. Além disso, obras como as de Bueno, Uruguai, Zacarias de Góis e Vasconcelos e Teófilo Ottoni, apenas para lembrar alguns dos políticos mais atuantes, entre 1860 e 1870, não exprimiam tão somente projetos ou possiveis interesses e pleitos mais imediatos. Os princípios ali propostos ou combatidos eram resultado de ampla experiência acumulada, desde a Independência, no trato de governar e de criar os fundamentos para o exercício da administração, da justiça e da feitura e aplicação das leis.

Como sugeriu Ilmar Mattos, particularmente os manuais de juristas como Bueno e Uruguai, constituem reflexões datadas sobre práticas, concepções e propostas que acabaram adquirindo o estatuto de "autoridade" e se tornando interpretações consolidadas sobre a construção e funcionamento do Estado imperial; versões que se banalizaram e se transformaram em suportes de uma visão por vezes dicotômica e simplificada das relações entre Estado e sociedade na segunda metade do século XIX - ora um estado forte e uma sociedade fraca, quando se amplificam as dimensões do Poder Moderador e do Conselho de Estado, ora um estado fraco e uma sociedade forte, quando se amplificam as dimensões dos legislativos, especialmente câmara e assembléias provinciais 25 . Segundo Mattos, essa oposição sem fim entre "burocratas" e "produtores" (entre Estado e sociedade) se desdobra em outras, a exemplo da polarização entre regime parlamentar e imperialismo da Coroa ou entre liberais e conservadores. Nesse caso, em especial, tem prevalecido a percepção de que afinal não expressavam matizes diferentes e posições contraditórias uma vez que se supõe que essas agremiações teriam tido percurso linear durante o longo tempo da monarquia no Brasil e se submetido ao Poder Moderador, definido por Faoro como o leme que dirigiu o Estado imperial desde o início de sua formação26.

0 artigo de Lima Lopes sugere percurso investigativo que está na contramão desses jargões. Procura mostrar que o Conselho de Estado não teve apenas importante papel legislativo, atribuição já bastante discutida por José Honório Rodrigues e por Oliveira Torres ${ }^{27}$. Além de apontar a relevância da operacionalidade do Direito em meio ao movimento de construção do Estado constitucional e representativo, o Autor indica como obras práticas de Direito registraram e difundiram orientações jurídicas realizadas por meio de avisos ministeriais derivados de consultas ao Conselho de Estado. Esses avisos ministeriais interpretavam regulamentos gerais e decorreram não propriamente da atuação do Conselho de Estado Pleno mas, sobretudo, das consultas feitas pelos ministros às seções nas quais 0 Conselho se dividia, o que repõe a partir de outra perspectiva as relações entre os poderes de Estado. 
Tratar do Conselho de Estado significa problematizar, ao mesmo tempo, o Poder Moderador, tomando o cuidado de não cair nas armadilhas discursivas de facções partidárias que, em momentos específicos do século $X I X$, para enfrentar-se nos espaços convencionais da política enviesavam o debate sobre o quarto poder, opondo argumentos que ora o denegriam ora o elogiavam, sem evidenciar no entanto sua importância para o funcionamento do Estado e para ações de governo.

Ademais, como observou o Autor, é pertinente confrontar disposições utilizadas no Brasil com outras experiências européias e americanas da época, reconstituindo-se os liames comuns a elas, dentre as quais a noção que prevê a existência de um poder neutro ou arbitral para encaminhar conflitos de natureza juridica e constitucional. Nessa perspectiva - que é a proposta pelo artigo - o Conselho de Estado representaria esse papel de magistrado, de poder neutro, agindo como Suprema Corte. Daí o caráter que pode ser conferido à seção de Justiça do Conselho: produz cultura jurídica, orientações gerais e analisa, também, questões relacionadas à carreira da magistratura, solucionando conflitos derivados da compreensão e da aplicação das leis.

Seguindo-se esse caminho, é possivel considerar o Conselho e igualmente o Poder Moderador como experiências específicas, formas históricas de manifestação do Estado liberal no século XIX, que aparece por meio de configurações diferenciadas dependendo do momento e do lugar, sem deixar entretanto de expressar os fundamentos da sociedade burguesa à época. Recoloca-se, desse modo, no campo da política e sob olhar singular, questionamentos relacionados sobretudo aos variados matizes do pensamento liberal e que têm permeado os estudos sobre a formação social que se projetou como nação a partir do esgarçamento da América portuguesa colonial. 